Session 3225

\title{
Early Design: Lessons and Strategies from SUCCEED
}

Mark Gordon and Dan Schrage

School of Aerospace Engineering

Georgia Institute of Technology

Joel Greenstein

Department of Industrial Engineering

Clemson University

Jack Hebrank

Department of Mechanical Engineering

North Carolina State University

Doug Hirt

Department of Chemical Engineering

Clemson University

Bill Mason

Aerospace and Ocean Engineering

Virginia Polytechnic Institute and State University

Tom Miller

Department of Electrical Engineering

North Carolina State University

Jim Nau

Department of Civil Engineering

North Carolina State University

\begin{abstract}
How can we involve our students in realistic engineering experience before the senior capstone design? The Early Design Megaproject component of the NSF-sponsored SUCCEED Coalition has tried various approaches over the last three years, and we learned many lessons. We share our experience in this paper. Schools include North Carolina State University, Georgia Tech, Virginia Tech, Clemson, Florida and North Carolina A\&T University. Departments include Aerospace, Mechanical, Industrial, Civil and Chemical Engineering. This paper describes what we've done and what we've learned.
\end{abstract}

\section{Introduction}

Traditionally, engineering design is reserved for the senior year in the curriculum, and very often it is reserved for the last semester of the senior year. The purpose is to bring together many aspects of science and engineering in a capstone design experience in which students analyze and synthesize information, make decisions, work in teams, propose and optimize a design, and perhaps even build a prototype. This approach 
has been used for many years, and the student's benefit from the experience because they begin to take a broader view of engineering and how it can be applied to solving real-world problems. The importance of these experiences then stimulates the following questions: Why wait until the senior year to implement engineering design? Why not introduce design earlier in engineering curricula?

These questions led to a major research thrust area within SUCCEED, an NSF-sponsored engineering education coalition composed of eight state-supported universities in the Southeastern United States.

SUCCEED's mission is to develop "Curriculum 21," a comprehensive redesign of undergraduate engineering education for the 21st century. As one of four topical centers within SUCCEED, the Center for Engineering Practice has a mission to "support engineering research and program activity that focuses on integrating engineering design and industrial practice throughout all stages of Curriculum 21." The NSF-funded coalitions EXCEL and SYNTHESIS also are involved with early design. Especially notable is the work at the University of Maryland with freshmen, ${ }^{1}$ which was recently recognized by Boeing as one of the top four educational efforts in the country. EXCEL and SYNTHESIS research has focused primarily on incorporating design in the freshman year.

SUCCEED has focused on integrating design throughout curricula. In the first year of funding, the Center for Engineering Practice sponsored approximately 10 early-design projects. At the end of the second year, these projects were grouped together into a team called the Early Design Megaproject. The purpose of the grouping was to obtain cross-fertilization among various efforts and to encourage pooled evaluation and assessment. Another unique aspect of this effort is the close coordination between the SUCCEED schools, made possible by the close geographical connection. The Megaproject meets at least three times a year to discuss our experiences and decide on future directions. The opportunity for design teachers across disciplines at different schools to meet and compare notes is an invaluable, if somewhat intangible, benefit. We are also evaluating the outcomes of these projects in terms of student satisfaction and retention rate compared to the overall school outcomes. The results will be reported when significant statistics are available. This will take several more years.

This paper presents descriptions of the individual projects conducted by the megaproject, followed by a discussion of the key aspects surrounding the early design experience, recommendations for accomplishing early design, and lessons learned from our experience. The megaproject has produced a manual that contains detailed descriptions for each of the projects. ${ }^{2}$ This manual is on the world wide web at the SUCCEED site, with the address: http://succeed.ee.vt.edu/edm/begin.html, which is part of the general SUCCEED page that is located at: http://succeed.ee.vt.edu/. Several articles describing the work also appeared in a recent issue of The Innovator, the SUCCEED Newsletter ${ }^{3}$ (this issue is not yet on the web).

The ten projects conducted are:

\section{The Projects}

\section{A civil engineering class that combines sophomores, juniors and seniors into teams that compete in a pedestrian-bridge or environmental-cleanup competition}

In this project, groups of selected sophomore, junior, and senior students engage in a one credit hour, semester-long design competition developed and coordinated by a panel of faculty and practicing civil engineers. The class is offered each spring semester, and by taking the course three times, students earn three design credit hours which can be used to replace an appropriate course in the civil engineering curriculum. 
Two aspects of this project are key features in the attempt to develop "early design" experiences for students. First, the vertically integrated design teams introduce sophomores and juniors to realistic civil engineering design problems which, in most curricula, are not addressed until the senior year. The expectation here is that the underclassmen (especially the sophomores and to a somewhat lesser extent the juniors) will be motivated by their interaction with the seniors as they experience the application of engineering theory in design. Thus, these students should perform better in their other lecture and laboratory courses. Second, the problems selected by the faculty and practicing engineers involve the design and fabrication of an actual physical model. Because most engineering homework and project work require only hand or computer calculations, the ability of the student to connect simple analytical models to physical problems is often lacking. It is anticipated that this "theory into practice" element of the course will again motivate and increase the student's interest in civil engineering.

\section{Bridging the Gap Between Theory and Application with a Competitive Multilevel Design Experience, James M. Nau and Philip C. Lambe, Department of Civil Engineering, and John C. Park, Department of Math and Science Education, North Carolina State University. See http://succeed.ee.vt.edu/edm/chap_2.html for complete details.}

2. An AE, IE, ME and EE interdisciplinary student team design, fabrication and test of unmanned aerialvehicle using concurrent design methodology.

Carried out by Georgia Tech, this project uses teams of students from all disciplines and all class levels to work on the Georgia Tech entry in the Association of Unmanned Vehicles Aerial Robotics Competition. There is a heavy emphasis on concurrent engineering and the modern approach to design practice. Students from many different disciplines participate, and graduate students are heavily involved as well as undergraduates. Perhaps the most significant aspect of this work is that students completely design, fabricate and test a complete air vehicle system. Students were most satisfied with the "hand-on" aspect of the project. They actually fly a remotely controlled (eventually to be autonomous) helicopter, with advanced sensors to allow the vehicle to pick up and deposit payload packages. Manufacturability is a strong consideration in achieving success.

Concurrent Engineering For Horizontal Integration of UAV Engineering Practice, Daniel P. Schrage, Mark A. Gordon, School of Aerospace Engineering, Ron Arkin, College of Computing, Steve Dickerson, School of Mechanical Engineering, George Vachtsevanos, School of Electrical Engineering, Georgia Institute of Technology, Atlanta, Georgia. See http://succeed.ee.vt.edu/edm/chap_3.html for complete details.

\section{A sophomore industrial engineering class that has student teams do a human-centered technology-related project}

This project focuses on the development and implementation of a cross-disciplinary, project-driven course on the product development process. A Clemson sophomore-level course (Industrial Engineering 201: System Design I) was offered for the first time in the fall semester of 1992 and has since been offered during the spring and fall semesters of each year. The course is required of all students in the industrial engineering major and is designed to be taken as the first course in the industrial engineering curriculum. The course prerequisites (Computers in Engineering and Physics I) are a part of the college-wide freshman engineering curriculum, enabling students in other engineering majors to take the course as well. A number of innovations have been introduced in this course, including: 
- Introductions to the product development process and engineering practice through course activities and real world design projects in the first course of the industrial engineering curriculum.

- An early and continual focus on the customer and users of the product.

- Integration of a variety of writing and speaking activities into the course to encourage active participation in the educational process, team building, and a class environment dedicated to the professional success of the students.

During each offering of IE 201, the nominal group technique is used in class with the students to determine ways in which the course might be improved. Questionnaires have also been developed and are used at the middle and end of each semester to determine the students' subjective satisfaction with the course. The results of these evaluations are used to drive the iterative design of the course to assure continuous improvement. They are also used to test a number of hypotheses regarding the students' satisfaction and attitudes toward the activities and content of the course. The results obtained thus far indicate that relative to other courses taken, students are more satisfied with their experiences in IE 201 along the following dimensions: atmosphere developed among the students and instructor; degree to which the instructor's knowledge was communicated; level of knowledge gained; level of ability gained in applying the knowledge; integration of speaking activities; and integration of design activities.

Cross-Disciplinary Education in Human-Centered Design , Joel S. Greenstein, Department of Industrial Engineering Clemson University See http://succeed.ee.vt.edu/edm/chap_4.html for complete details.

\section{Electrical engineering multi-semester entrepreneurial teams develop the technology and business aspects of product-based projects.}

In the past three years the Department of Electrical and Computer Engineering at NCSU has established an entity called the Undergraduate Design Center (UDC) as a vehicle for supporting senior capstone design projects. Most UDC projects are supported by industrial sponsors who pay a membership fee to the UDC.

The success of the UDC has been overwhelming, as attested by students, faculty, and industry participants. In end-of-semester surveys, more than $50 \%$ of the seniors participating in a capstone design project through the UDC have stated that it was the best course they have taken at NCSU. This project seeks to extend this type of positive experience from the senior level down to the lower levels.

The focus of the project has been the development of a novel approach to extending the kind of design experience provided by the UDC to underclassmen. A new multi-semester course called the Engineering Entrepreneurs Program has been developed. The course is available to undergraduates at all levels. Each student enrolling in this program becomes a member of a project team, and is eligible to remain a member of that team until graduation. Each student contributes to the team's project at level commensurate with his/her background. We believe that the concepts of vertically integrated student teams and multi-semester participation are the key ingredients for the success of this program. 
The theme of entrepreneurism came about as a result of the observation that the nature of these project teams is not unlike that of a small start-up company developing a new product. It was felt among the participants that this theme would be interesting to students (who sign up for this experimental course purely on an overload basis), and relevant to SUCCEED's mission of meeting the educational needs of engineering graduates of the 21 st century.

We have also found the engineering entrepreneurism theme to be of great interest to large companies which employ our engineering graduates. IBM has participated in the program since its beginning, supporting the program with equipment and personnel. They have found the model of engineers working in small teams with broad responsibilities for a product to be relevant to their new business style. As a result, many of the students participating in the Entrepreneurs Program have been offered co-op positions by IBM, and Entrepreneurs Program presentations to the IBM Systems Networking division in RTP, NC, have become a biennial event.

The Engineering Entrepreneurs Program, Thomas K. Miller III , H. Troy Nagle Clarence J. Maday , David E. Van den Bout and James J. Brickley, North Carolina State University , Tony L. Mitchell, John C. Kelly North Carolina A. \& T. State University. See

http://succeed.ee.vt.edu/edm/chap_5.html for complete details.

\section{Chemical engineering students that learn engineering science courses in the context of an evolving description of an industrial process.}

We have taken the first steps to alleviate student complaints that they never see anything practical by giving the students design projects (case studies) in the early stages of their academic careers and having them work on that project as they proceed through a portion of the curriculum. This program is similar to work being performed at West Virginia University by Bailie et al., ${ }^{4}$ the major exception being how to handle a program of this type when a large number of co-op students are continually rotating on and off job assignments.

The concept of an evolving design project is best understood by describing, in general terms, a particular case study. The case study described below is applicable to chemical engineering in which the design elements are unit operations, such as pumps, heat exchangers, reactors, and distillation columns. However, this example of an evolving design project is meant to serve as a model that can be adapted to other engineering disciplines.

The case study to be examined is taken from Felder and Rousseau. ${ }^{5}$ The case study involves the fermentation of grain to produce ethanol. It is given to the students as first-semester sophomores in the first chemical engineering course (ChE 201), and it initially consists of a written description of a chemical process. Groups of students sift through the description and then develop a flowsheet of the process as they envision it. This gives the students an opportunity to see how the various pieces of equipment can come together to form a successful design. The students then perform detailed material and energy balances around the entire process and around selected pieces of equipment (material- and energy-balance problems associated with this case study may be found in the reference cited above). Depending on the timing of the case study during a semester, the material and energy balances either replace or reinforce homework problems. It is emphasized to the students that, at this early stage, they are not expected to know every detail of the design, but that by the end of the curriculum they will be able to understand all of the design elements. 
The unique part of this early-design experience is that the students continue to work on the same case study through a critical portion of the curriculum.

Evolving Design in Chemical Engineering, Douglas E. Hirt and Charles H. Barron, Jr., Department of Chemical Engineering , Clemson University. See http://succeed.ee.vt.edu/edm/chap_6.html for complete details.

\section{Civil engineering students that use an actual civil engineering structure as the basis for a three-course} sequence.

An approach being explored in the Civil Engineering Department at NCSU is to introduce a structural system (e.g. building), to the students as a first step toward seeing how their studies lead to an actual product. This type of introduction captures their interest, and then the structural system is used to develop a case history. This approach is similar to the way medical students are exposed to a human body and its anatomy, which is followed by introduction of diagnostic procedures and the know how for preventive and corrective measures for remedial solutions. The potential impact of this approach would be that the students would have a better understanding of the design decisions, process and the methodology. This approach also helps the students develop conceptual design ability. The anticipated results of such an approach would be that the students would get involved in engineering practice at an earlier stage and thereby the chances of their retention and success are be increased.

Interaction of Structural Engineering Design and Practice in the Civil Engineering Curriculum, Shuaib H. Ahmad, Paul Zia, Department of Civil Engineering, North Carolina State University. See http://succeed.ee.vt.edu/edm/chap_7.html for complete details.

7. An aeronautical engineering design project that combines freshmen and seniors working together in teams working on the national airplane design contest

This freshman/senior design project is an attempt to accomplish several important design and educational goals by having freshmen and seniors work together on the conventional capstone design project. The project has been used with good success in both Aerospace and Ocean, and Mechanical Engineering. We have implemented the concept quite simply. In AE, the senior design course is two semesters long. Senior teams are formed during the first semester. The freshmen take Introduction to Engineering each semester. During the first semester they are told about the vertically-integrated program, where they can participate in a "senior" design team and use the work they do there as a replacement for the CAD project in the second semester of Introduction to Engineering. Interested freshmen volunteer. Those selected work with a senior team in the second semester. The selection is based on interest in the specific major (AE or ME at present) and a grade of "C" or better in the fall Introduction to Engineering course. In the senior course they are full participants in the final report and presentation.

Vertically Integrated Design, W.H. Mason, N.S. Eiss, Jr., R.H. Pusey and J.F. Marchman III, Departments of, Aerospace and Ocean Engineering, Mechanical Engineering, and Engineering Fundamentals, Virginia Polytechnic Institute and State University. See http://succeed.ee.vt.edu/edm/chap_8.html for complete details.

\section{A multi-semester aircraft design course.}


This project began in March 1994 and it reflects a new approach to the instruction of Aircraft Design in the Department of Aerospace Engineering, Mechanics and Engineering Science (AeMES) at the University of Florida. It crosses the traditional boundaries between semesters, disciplines and years of education from junior to graduate level. Built around the SAE Heavy-Lift Aircraft Design Competition entry, this experiment in teaching design has multiple goals:

- expose the students to the broad aspects of the design discipline, from the product requirements through conceptual and detailed design, to testing and utilization.

- emphasize collaboration by maintaining a nucleus of students formed at the beginning of the activities through the completion of the "course-project", several semesters later.

- increase student retention in the program by ensuring continuity through the years of education and by strengthening both the relationship between design and other technical and non-technical disciplines, and by developing social bonds within the group.

The course spans four semesters and carries 11 credit hours. Upon full implementation it is expected that it will replace the aerospace capstone design course. By end of March 1995 Phase 1 of the project was completed. This includes:

- conceptual design: two configurations have been selected, a joint wing and a conventional configuration. Both configurations were analyzed, they will be manufactured and tested before a selection for the competition decision will be made. The analysis will include aerodynamics, stability and control, and performance.

A Multi-Semester, Introductory Aerospace Design Course, Corin Segal, Department of Aerospace Engineering, Mechanics and Engineering Science, University of Florida. See

http://succeed.ee.vt.edu/edm/chap_9.html for complete details.

\section{Seniors teaching and mentoring electrical and computer engineering sophomores about design and management skills.}

In the fall semester of 1994, the Department of Electrical and Computer Engineering at North Carolina State University offered an "Early Engineering Skills and Design" course to sophomores entering the department. The course was designed to provide the sophomores with skills that would help them succeed in a very tough curriculum. It was also designed to enlighten these students with respect to what electrical and computer engineers did after they graduated, and it was designed to be fun.

The other interesting attribute of this sophomore course was that it was taught by seniors in electrical and computer engineering. The seniors were to serve as co-instructors with the faculty and provide guidance as well as knowledge. Of course, the seniors would gain a great deal from this opportunity also. It was hoped that the sophomores would relate more closely with instructors who had recently successfully accomplished the rigors of the ECE curriculum.

When the course was designed, the goals were to: (1) get incoming students excited about electrical and computer engineering, (2) show students how to make the most of their education, (3) provide students with "hands-on" engineering projects, (4) challenge the students to be creative, (5) force the students to make several oral presentations, (6) improve the students' technical writing skills, (7) promote team building activities, (8) highlight the opportunities provided to engineering graduates, (9) give deserving seniors a 
chance to teach and use the skills learned during their academic career, (10) put design into the curriculum at a very early stage, and (11) prove that bright, energetic sophomores can do good, basic engineering and design projects with only basic math and science course backgrounds. The course met twice a week (1 one hour lecture, 1 one hour and 40 minute practicum) for thirteen weeks. Each week will be described in detail below.

An Early Engineering Skills and Design Course, Dr. John C. Sutton III, Ms. Ashley B. Donahue, Ms. Monica J. Shakib, Ms. Angela G. Powell, Department of Electrical and Computer Engineering, North Carolina State University. See http://succeed.ee.vt.edu/edm/chap_10.html for complete details.

Based on the results of these projects, the rest of the paper describes our consensus view of the approach to introducing design into the curriculum early. Lessons and experiences are given.

\section{Design is a process}

Most of these projects are based on the concept that design is a process, and learning this process requires that students engage in that process by working on a realistic problem. The project can be based on a competition, a perceived need or even emanate from students who are required to determine a need or locate a problem.

An important element of teaching design is to provide a generic design process that can be applied to a wide range of problems. In general, the design process model includes defining the need, exploring the need, generating alternatives, analyzing and selecting alternatives, and describing the solution. This generic model for design is similar to the model for creative problem solving described by Lumsdaine and Lumsdaine. ${ }^{6}$

A central theme in the design process is decision making, and one approach to the teaching and practice of design is to focus on the decision-making function and to implement a process of doing design that provides support for decision making. The emphases on total quality methods and multi-disciplinary design encourage use of tools that record customer requirements and translate these into design requirements. Additionally, the use of tools for decomposition and recomposition allows the student to understand the products and their related processes, such as development, manufacture, and support. This is a key component in design education, and has been designated as an educational requirement by several studies.

There are many different design processes, however, each must possess the ability to relate requirements to design criteria in order to evaluate alternatives. The Top Down Decision Support Process can be used in early design projects because it provides a framework for understanding and specifying the problem, and allows for evaluation of alternatives. This enables the students to understand the critical process of creating technical design requirements from customer requirements and later evaluating alternatives by how well these alternatives satisfy the customer. In addition, methods specific to particular disciplines can be easily integrated to support more sophisticated analysis as the student progresses through the curriculum. The process, together with the questions that must be answered at each stage, is shown in Figure 1. For each stage of the process, methods and tools from quality and system engineering support the formulation and evaluation of the design. Some of the methods used include construction of Quality Function Deployment Matrices, flowcharting of activities, and establishment of criteria functions. The criteria building process described in Pugh $^{7}$ was utilized in the Voice of the Customer Project at Georgia Tech. 


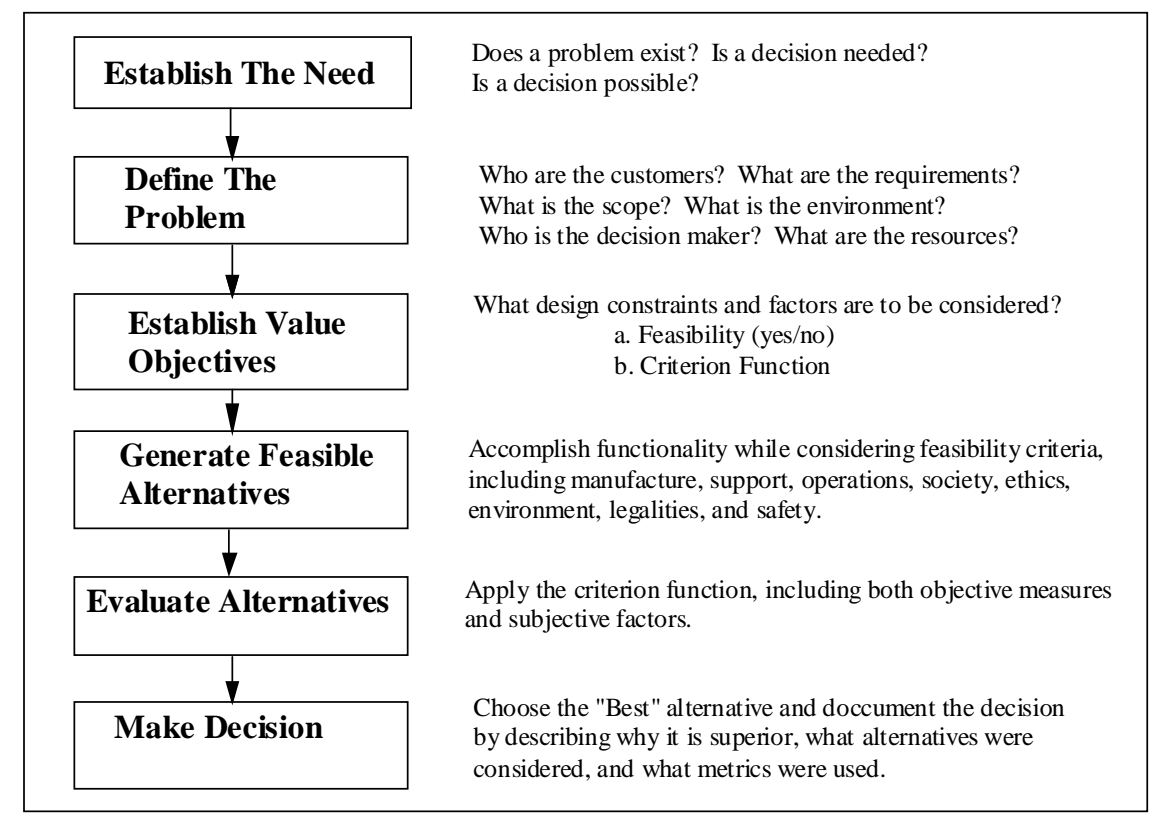

Figure 1: Top Down Decision Support Process

One of the values of teaching students a formal design process is that it can be used in subsequent courses and helps the student understand and retain the elements of the design process. Furthermore, students who worked in teams in subsequent courses can disseminate the decision support process to classmates. It is this type of learning that is a central objective of the Early Design Megaproject.

\section{Why implement early design?}

Early design experiences have multiple benefits to undergraduate engineering education. Many engineering students are motivated by the desire to understand and immerse themselves in real-world problems and technology. Encountering design experiences early motivates these students and helps them to appreciate their interest in doing engineering design. Design experiences motivate design-oriented students in engineering science classes, which may be less interesting to them, by showing them why the material is needed and providing a context for learning the material. Similarly, retention of students is improved because students are actively involved in their selected engineering discipline.

Many of these design projects include integration of multiple disciplines of engineering to enhance the sophistication of the design. Experiencing multiple disciplines benefits by helping the student to define his/her selected discipline and to understand the discipline-specific value of the analytical tools and techniques that they are learning. Interdisciplinary projects also encourage the students to work in teams with assignable roles providing early and repeated practice in the team environment that is common in industry, government, and academics.

Other projects combine multiple stages of students (for example, freshmen and upperclass students on the same team). Again the different technical abilities cause team members to define their roles, with seniors taking the more challenging technical tasks and freshmen doing less sophisticated, but no less important tasks. Seniors have the opportunity to learn and practice leadership skills. One very significant advantage of multistage teams is the mentoring that occurs. Seniors can help newer students learn academic survival skills and 
help them understand the overall context for the material that they study. As collaborative learning experiments show, seniors improve their understanding of technical material by explaining it to others, and a younger student may benefit from receiving one-on-one instruction.

Another basic reason for providing early design experiences is to provide an academic base for teaching more sophisticated concepts of design to undergraduates. The number of issues surrounding design, from theoretical design methodologies, such as Suh's theorems ${ }^{8}$ or concurrent design, are difficult to include in a first level design course for many reasons. For example, a large number of topics must be considered, and students have difficulty in appreciating the concepts without ever having been a part of a design effort. Students who only encounter a design experience at the capstone level lack design expertise, which can be taught to students after having completed a design project.

Lastly, early design experiences provide an environment for students to learn the communication and management skills that have been identified as key to the success of undergraduate students (ASEE Council of Deans Report $\left.{ }^{9}\right)$. Verbal and written design reports, seeking information from experts or vendors, and sharing and convincing other team members of technical points of view provide opportunities for students to practice and appreciate the importance of communication. Teamwork is also a key management skill needed by most practicing engineers, and the projects associated with early design provides an opportunity for students to develop these skills. Improvement of communication and management skills early in a student's career benefit the student in professional life and help ensure a successful academic experience.

\section{Team Building, Vertical Teams, and Mentorship}

One of the key aspects of modern engineering is teamwork. Industry continually stresses the need for engineering students to be able to work effectively in teams, and as in almost all design programs, the early design megaproject uses the team approach almost exclusively. Although teamwork is universally recognized as important in engineering education, there is little guidance available on how to work with student teams. Students cannot be expected to work effectively as teams without direction. Even then, it is not unusual for teams to have problems. Often, the team experience is part of the senior capstone design class. However, the Early Design Megaproject has demonstrated that students can be introduced to the team experience much earlier. Forming teams from different classes, like sophomores with seniors, is a very effective means of introducing students to the team process.

\section{Team Building}

Student teams are different from industrial teams because of the short duration of the team (at most nine months) and because they may have significantly different motivations. But perhaps the biggest problem is that students often perceive teamwork as getting together to work on a design in the same manner that they would work on a typical class homework problem. Students must understand that a team requires each member to be individually responsible for one aspect of the design. Within this framework, the students need to realize that the team must be organized to decide long-term goals (typically to satisfy the semester design requirement) and short-term objectives to define a plan to reach the goal. The team must decide exactly what decisions have to be made, and what needs to be done to obtain the information needed to make the decision. Then, each member must provide one part of the information required. Using everyone's contributions, the team can then make a rational design decision. Students soon learn that engineering projects require too much work to be done entirely as a group homework problem. To survive, the workload has to be divided and each 
team member must provide independent results from their own work. For example, in aircraft design this often means that one student provides aerodynamics results, while another does structural analysis. The interdependence of these tasks produces considerable peer pressure independent of the instructor. Students find out the importance of providing each other data as required and with reliable accuracy. They also find out quickly how important it is to stay focused on objectives and only work on tasks specifically required to provide the group with the information required to make design decisions. Finally, team leaders often have to learn that they can't be dictators, but must lead teams through consensus building. Because they haven't had the experience, they may assume that in industry it is possible to dictate.

In forming the teams, it becomes important that each student has a clearly defined responsibility. The students should work together to decide what the various responsibilities are and decide who will be responsible. In aircraft design this typically means that one student will be responsible for aerodynamics, while another is responsible for the avionics suite, etc. Teams may be required to designate a leader. It is not infrequent in a two-semester design sequence for a team to replace a leader. This usually occurs because the "leader" has not demonstrated an ability to organize, set schedules and establish a clear theme for the group to follow. Some leaders may be aggressive, highly structured and demanding. Although a team may not be happy with this situation, a team usually doesn't replace the leader in this situation. To help with team organization, the course instructor should discuss the importance of a good organization and clearly defined responsibilities early in the semester and teams can be required to present their organizational plan to the class.

Team size is another issue. The consensus among experienced design teachers is that five or six member teams are about the right size. This provides enough capability to do significant projects, while remaining small enough to maintain good communications. Teams with 10-12 members tend to subdivide into subgroups and often have problems.

Grades for group projects can sometimes be an issue. Many instructors assign the entire team a group grade, and then each member does a peer review of the other team members to generate individual grades. Students rating above the mean may have their grades raised, while students ranking below the mean may have their grades lowered. Although students are initially reluctant to differentiate among team members, after the hard work and stress of preparing design reviews and reports, they readily identify the outstanding and weak members. The peer review usually agrees with faculty observations, however, in cases where a team forms factions, the instructor should be prepared to use another method to generate grades. Sometimes students are not aware that the rest of the team is not happy with their performance. To help team members improve their performance, a mid-semester or earlier peer review can be done. Team members can be told if they are considered to be weak team members. When students realize that their grades will affected by the views of other students, many actually respond and improve their team performance. This is the first time in engineering school where working well together, one of the most important aspects of engineering, actually counts.

\section{Vertical Design}

The Megaproject use of the term vertical design means teams made up of students from several different classes. An example of this is at Virginia Tech where freshmen work on "senior" design teams. Here, the seniors work for the full year and the freshmen join the teams at the beginning of the second semester in lieu of their freshman engineering project. Typically two freshmen join a team of six to eight seniors. The students must start with their design team at the first meeting of the semester and furthermore, freshmen attend the final design presentations given at the end of the Fall semester as a way of finding out about the design 
project. In the second semester the teams develop a selected design in detail with the freshmen taking responsibility for a particular part like the landing gear or the crew station design. In each case, the freshmen can make extensive use of their CAD program.

Another example of vertical design is the Engineering Entrepreneurs Program at NCSU. Here, students from all classes participate with the seniors as team leaders of a group of underclassmen. This extends to making the seniors responsible for assigning and checking on the work of the underclassmen so that valuable management and leadership skills are developed. Advantages to using multiclass groupings are that the numbers of students from different classes is not fixed so that student ratios do not hinder scaling it up to include all students, and projects and students can span multiple semesters.

\section{Mentoring}

Students working together in cross-class projects provide extremely effective mentoring. The apprentice role that emerges extends beyond the design class itself. Freshmen get insight into the importance of the engineering science classes and a wide perspective on engineering practice, as well as practical advice on academic skills such as time management. This is simply not available in standard classes. The flavor of mentoring can be gleaned from the comments by two freshmen from the Spring 1995 experience at Virginia Tech:

"I felt a little overwhelmed with the project at first, considering my lack of knowledge, but I soon got used to what was expected and felt very comfortable working on the team. Overall, this was a very rewarding and educational experience."

"I enjoyed working with the seniors and thoroughly enjoyed the experience. It was an excellent opportunity and I learned far more than I would have in my Engineering Fundamentals design project."

Several key resources are available to use in team building. They include Scholtes, ${ }^{10}$ the pocket sized book by Brassard and Ritter, ${ }^{11}$ the much larger volume by Brassard, ${ }^{12}$ and the latest pocket volume by a group from GOAL/QPC and Joiner Associates. ${ }^{13}$ Finally, further references can be found in the html version of a recent paper ${ }^{14}$ by looking at http://www.aoe.vt.edu/aoe/faculty/Mason_f/ACDesP/ACDesPgmVPI.html (If the text of this paper is actually available electronically than a copy to the URL locator is simple).

\section{Using Assessment to Drive Continuous Improvement of Early Design Experiences}

Assessment of the early design experiences can suggest ways of improving the experiences, as well as indicate how well the experiences are working. Both of these kinds of information are important: Once you have used one assessment to suggest "interventions" and introduced these "improvements," follow-up assessment is required to find out whether the interventions really did improve the design experience.

The length of the intervention-assessment cycle may be as short as one class meeting or as long as a course term. In the following paragraphs a few simple assessment techniques are outlined. It is recommend that you NOT try them all your first time around! As you become familiar with the insights and time requirements associated with one, consider adding another to your tool kit.

The One Minute Quiz 
The "one minute quiz" helps to monitor and adjust the pace and direction of design experiences from day to day. One form of this quiz asks three questions just prior to the end of a class meeting:

1. What was the most important thing that we did today?

2. What didn't you understand?

3. What do you want to know more about?

A quick review of the quiz results between class meetings guides the approach to the next class meeting. It also suggests how the approach to the day's activities might be changed the next time the course is taught.

\section{The Midterm Open-Ended Questionnaire}

Over a somewhat longer time frame, an open-ended midterm questionnaire can be used to provide a "reality check" on the design experience while there is still time to make some mid-course corrections. Students might be asked to take ten minutes at the beginning of class to complete a one page questionnaire that asks them to respond to the following questions:

1. What suggestions do you have to improve the design experience?

2. What do you like best about the design experience?

3. What do you like least about the design experience?

4. What suggestions do you have to improve the instructor's teaching?

While some of the answers the students may provide will have to be filed away for another time ("Give us projects that don't require us to travel half way across the state."), other answers may be surprisingly easy to respond to once you become aware there is a problem ("Is there any way you could provide our teams access to a facility where we can work together outside of our scheduled lab time?). And students seem to be particularly appreciative (and pleasantly surprised) when the teacher responds quickly and positively to some of their suggestions. If nothing else, your actions demonstrate that the philosophy of continuous improvement you are trying to instill in their work is something you take seriously with regard to your own.

\section{The Nominal Group Technique}

Toward the end of the design experience, the nominal group technique can be a useful methodology for determining ways you might improve the experience the next time. The description provided here is drawn from Michael Brassard and Diane Ritter ${ }^{11}$ but the approach is also outlined in other useful references (e.g., Scholtes ${ }^{10}$ ). Those of us who have used this technique usually dedicate a class period to the exercise, but if you already happen to have taught your students the technique for use in their own design teams, it can probably be done in half that time.

First, ask the students as a class to brainstorm responses to a question similar to the following: "In what ways might I change this design experience to make it a better one for the students who participate in it next time?" Write the question on the board and answer any questions the students have about what it means. Appoint a student to serve as the facilitator for the exercise and have this student write every idea voiced by the students on a flip chart or board so that all the ideas are visible to everyone. Remind the students that it is not appropriate to criticize ideas while brainstorming and that the group should do its best to work quickly. (So 
as not to inhibit the students' responses, it may be best to leave the room after this, checking in from time to time to move them on to the next steps in the process.)

Once the brainstorming phase has been completed, the facilitator should ask the group to review the list of ideas generated to combine duplicates and clarify meanings of any unclear statements. The facilitator should always ask for the group's permission and guidance when combining or changing statements. Then the facilitator should put a letter $(\mathrm{A}, \mathrm{B}, \mathrm{C}, \ldots)$ in front of each remaining idea on the flip chart. Each member of the group should then write on a piece of paper the letters corresponding to the ideas produced:
A
B
C
$\cdot \cdot$
..

On his or her piece of paper, each person should then vote on which idea is most important, second most important, and so on. If there are ten or fewer ideas in the list, all the ideas can probably be ranked (e.g., if there are eight ideas, rank the most important idea an 8, the second most important a 7, etc.). If there are more than ten ideas, it may be better to rank only the top "one half plus one" ideas (e.g., if there are 25 ideas, rank the most important idea a 13, the second most important a 12, etc.). Note that since these individual rankings will soon be combined, it is important that everyone use the same largest number for the most important idea. This "reverse ordering" results in a "zero" value being assigned to ideas that individuals do not include in their rankings.

Next, the facilitator combines the rankings of all the members of the group by adding up the ranks provided for each idea:
A: $5,4,5,3,3=20$
B: $3,2,3,1,1=10$
C: $4,3,5,2,4=18$

The ideas can now be ordered from most important (highest total) to least important (lowest total) and the results can be discussed with the group. The results can then be documented in writing and used to drive the design of the design experience next time for continuous improvement.

\section{The End-of-Semester Rating Scale Questionnaire}

While the nominal group technique suggests ways in which your design experiences might be improved, it doesn't guarantee that these suggested "improvements" will in fact improve the design experience. An end-of-semester questionnaire, used consistently, can be a useful means for tracking whether your interventions appear to be achieving their intended objectives. Members of the megaproject have worked together to develop a questionnaire that might be useful to us in assessing the effectiveness of early design experiences. That tool is included in the appendix. You might wish to use some of the questions from this questionnaire and develop others of your own that are tailored to the specifics of your own design experience (and to your own hypotheses as to what benefits you believe should result from the design experience you are providing). Be careful not to include too many questions in your questionnaire. Your students' patience at the end of the semester has its limits. And unless you take some time to automate the process of compiling the data from the questionnaire, your patience in tallying the results will probably be even more limited. Ask the questions you consider to be most important in tracking the quality of the design experience and keep a running tally of how the students feel you're doing along these dimensions from semester to semester. These 
results, over time, should help you to determine how well your experience is working, along what dimensions it needs to be working better, and along what dimensions your most recent interventions have been perceived by the students as being improvements.

To sum up, periodic assessment of your design experiences using methods such as those implemented in the Megaproject efforts and described above can be used to determine ways in which the experiences can be improved. This, in turn, can be used to drive the iterative refinement of the design experiences to assure their continuous improvement.

\section{Summary}

This paper has described several on-going innovative approaches to include design early in the curriculum. It then addressed some of the why's and how's of doing design projects early in the engineering curriculum. More information about the practical aspects of accomplishing an early design course is addressed in the Early Design Manual. This manual is available on the SUCCEED WEB server as given above and again here: http://succeed.ee.vt.edu/edm/begin.html

\section{Acknowledgments}

The work reported in this paper was the result of a team effort on the part of many faculty and students at the various schools participating in the SUCCEED Coalition Early Design Megaproject. We gratefully acknowledge their contributions, as well as the National Science Foundation for supporting the work.

\section{References}

1. Meade, Jeff, “Change is in the Wind," ASEE PRISM, May 1993, pp. 20-24

2. SUCCEED Early Design Megaproject, "Early Design Experiences: A Manual for Addressing Design Early in the Engineering Curriculum," May 1995. Available from Jack Hebrank at hebrank@eos.ncsu.edu.

3. Yocum, Carole, Ed., , The Innovator, the SUCCEED Newsletter, No. 4, Winter 1995, Available from the Chemical Engineering Dept., University of Florida, Gainesville, FL 32611-6005.

4. Bailie et al., Chemical Engineering Education, 28, 52 (1994)

5. R. M. Felder and R. W. Rousseau, Elementary Principles of Chemical Engineering, Second Edition, John Wiley \& Sons, 1986, Chapter 14.

6. Lumsdaine, E., and Lumsdaine, M. (1995), Creative Problem Solving, New York: McGraw-Hill.

7. Pugh, S. (1991). Total design: Integrated methods for successful product engineering, Workingham, England: Addison-Wesley.

8. Suh, N.P. (1990). The Principles of Design, New York: Oxford University Press 
9. ASEE Council of Deans Report (1994), Engineering Education for a Changing World, Washington D.C.: American Society of Engineering Education.

10. Scholtes, P. R. (1988). The team handbook: How to use teams to improve quality. Madison, WI: Joiner Associates.

11. Brassard, M., and Ritter, D. (1994). The memory jogger II: A pocket guide of tools for continuous improvement \& effective planning, Methuen, MA:

GOAL/QPC , 1994 (1-800-643-4316)

12. Brassard, M. (1989), The Memory Jogger Plus+, Featuring the Seven Management and Planning Tools, GOAL/QPC 1989 (1-800-643-4316)

13. GOAL/QPC and Joiner Associates, The Team Memory Jogger, GOAL/QPC , 1995 (available by calling 1800-643-4316)

14. Mason, W. H., "Aircraft Design at Virginia Tech: Experience in Developing an Integrated Program," AIAA Paper 95-3893, given at the 1st AIAA Aircraft Engineering, Technology, and Operations Congress, Sept. 19-21, 1995, Los Angeles, CA

\section{Biographical Information}

BILL MASON is a Professor in the Aerospace and Ocean Engineering Department at Virginia Tech. He teaches the "senior" aircraft design course, which now has freshmen too, as well as a sophomore Introduction to AOE Design course and Applied Computational Aerodynamics. Prior to coming to Virginia Tech he spent 15 years in industry at the Grumman Aerospace Corporation. His research is in multidisciplinary design.

JACK HEBRANK is an adjunct associate professor in the Mechanical and Aerospace Engineering Department at North Carolina State University. Fourteen years ago he introduced industrially sponsored projects into their ME Capstone Design Course. He is the Director of the Center for Engineering Practice within the SUCCEED Coalition. His research interests include biomechanics and industrial controls.

DOUGLAS HIRT is DuPont Assistant Professor of Chemical Engineering at Clemson University. He received his B.S. and M.S. degrees from Virginia Tech and his Ph.D. from Princeton University, and was a NAS/NRC Research Associate at NASA Langley Research Center from 1989-90. He received the Dow Outstanding New Faculty Award from the Southeast Section of ASEE in 1995.

JOEL GREENSTEIN is a associate professor of industrial engineering at Clemson University. His current research and teaching focuses on integrating principles and methodologies for the design of usable systems into the overall product and system design process. Dr. Greenstein is a member of ASEE.

MARK GORDON, formerly of the School of Aerospace Engineering at the Georgia Institute of Technology, was the project leader on the Unmanned Aerial Vehicle project which UAV competition. 
DAN SCHRAGE is a Professor in the School of Aerospace Engineering at the Georgia Institute of Technology, and is one of the Directors of the Systems Design Laboratory. A graduate of the US Military Academy at West Point, he had a long career in Army aviation, including advanced development programs. Much of his current work focuses on graduate design education and research in concurrent engineering.

TOM MILLER is a Professor in the Department of Electrical Engineering at North Carolina State University and also responsible for the engineering computing systems. His background is in biomedical engineering and instrumentation, and he has extensive experience with small businesses and startup high tech companies.

JIM NAU is in the Department of Civil Engineering at North Carolina State University, where he like to have students build bridges. 